\title{
Recognising Similarity in 'Angers' Across History
}

\author{
W. Gerrod Parrott \\ Georgetown University, Washington, D.C, USA \\ parrottg@georgetown.edu
}

\begin{abstract}
A family-resemblance approach to categorisation, such as that developed by Wittgenstein, provides a basis for conceiving how various historical types of 'anger' can be recognised as similar despite their variability and lack of core defining features. Thomas Dixon's essay applies this approach in a way that avoids radical relativism and acknowledges general human emotional capabilities. His approach may arguably be extended to commonalities between emotions of humans and animals, which would have interesting implications for the history of emotion.
\end{abstract}

\section{Keywords}

anger - animal emotions - categorisation - emotion - history

Historians of emotion face a difficult problem. They must simultaneously assert that their topic - be it 'anger', some other emotion, or 'emotion' itself - is in historical flux, while also asserting that their history addresses a coherent topic, that it is a history of something despite that something's inconstancy. Their problem is how to characterise topical coherence in the face of variability. Thomas Dixon's essay aptly characterises this dilemma and takes important steps toward its resolution. In my commentary I want to applaud those steps while urging that they venture even further so as to arrive at the general themes that underlie families of human emotions and the similarities that exist between the emotions of humans and those of other animal species.

When it comes to historical flux, Dixon's essay summarises what historians have always done best. He reviews the formidable historical evidence favouring emotional pluralism and joins it with similar arguments by anthropologists, linguists and psychologists. No one familiar with this evidence can 
be comfortable allowing noncontemporary 'anger' to stray outside its quotation marks.

When it comes to topical coherence, however, Dixon's essay raises a question that has received considerably less attention from historians. Why have historians neglected the question of Dixon's title, 'What is the history of anger a history of?' Historians' focus on contextualising emotions within particular cultural and historical settings foregrounds emotions' uniqueness, so does not foster attention to their similarities. When pushed to an extreme, this emphasis can lead to a radical relativism in which the emotions of different times are not merely distinguishable but absolutely incomparable. The historical claim that social, cultural and linguistic factors can shape emotions becomes implausibly stretched to being that emotions are shaped only by these factors.

One should therefore applaud Dixon's determination to consider broader similarities and to describe them in terms that are compatible with historians' concerns. A substantial portion of his essay describes what the history of anger is not a history of - it is not about a fixed entity, a basic emotion, an English word or a modern category. ${ }^{1}$ What anger is, Dixon asserts, is a set of interrelated components whose connections can be understood genealogically. His view of 'anger' through history is akin to viewing a length of rope as being composed of interwoven fibres, none of which need run through its entire length.

It is worth noting that the problem of topical coherence is ubiquitous. The problem can occur on vastly smaller historical time scales, such as when comparing one person's 'anger' in the morning to that same person's 'anger' later the same day - no two instances of 'anger' are ever identical, so the question of what makes them both 'anger' remains. The problem occurs also when comparing emotions from different contemporary cultures; cross-cultural psychologists must confront issues of translation equivalence when comparing 'anger' or 'shame' across cultures. ${ }^{2}$ But, to consider something utterly unlike emotion, astronomers have struggled to define what makes something a 'planet'. As planetary astronomers expanded their knowledge of terrestrial planets, gas planets, asteroids, comets and Kuiper belt objects, they found it increasingly

1 It needs to be pointed out that the sense of basic emotion that Dixon objects to was substantially revised by psychologists in the early 199os and is no longer espoused. It is now a straw man that need not be attacked, a dead horse that needs no further beating. For discussion of more recent approaches see William A. Mason and John P. Capitanio, 'Basic Emotions: A Reconstruction,' Emotion Review 4, no. 3 (2012): 238-44; W. Gerrod Parrott, 'Ur-Emotions and Your Emotions: Reconceptualizing Basic Emotion,' Emotion Review 2 no. 1 (2010): 14-21.

2 Alejandra Hurtado de Mendoza et al., 'Emotion Terms, Category Structure, and the Problem of Translation: The case of Shame and Vergüenza,' Cognition and Emotion 24, no. 4 (2010): $661-80$. 
difficult to define what separates planets from non-planets and even whether the category of 'planet' remains useful. ${ }^{3}$ Likewise, as biologists studied an everexpanding variety of living things, they found that they cannot adequately define what 'life' is. ${ }^{4}$

There are two basic solutions to this problem. One, derived from Aristotle, asserts that there is some stable core of features that is necessarily present amidst the historical fluctuation - some cluster of properties that are shared by all members of a category. The other, derived from Wittgenstein, denies any constant essence at the core of a category and proposes instead that category members share only a greater or lesser 'family resemblance' to one another. ${ }^{5}$ In many disciplines there is something like a tug-of-war between the two approaches. For example, some planetary astronomers believe that there must be some quality shared by all true planets and that it is astronomers' job to figure out what it is. Other planetary astronomers believe that there is no reason to expect that a set of objects first identified by naked eye as stars moving through the zodiac should continue to seem a tidy category after examination by telescope and interplanetary probe. ${ }^{6}$

A similar tug-of-war can be seen with a category such as 'anger'. The Aristotelian answer is that there must be some essence shared by all angers and that consensus about its definition should be sought. That approach has been employed not only by basic emotion theorists but by virtually every discipline that studies anger. ${ }^{7}$ The Wittgensteinian answer is that it is neither possible nor desirable to discover a fixed set of features that define anger. The most common version characterises category membership not as either-or but as a gradient of similarity to central prototypes. The Wittgensteinian model implies that categories have fuzzy boundaries, not sharp ones. ${ }^{8}$

Dixon's Wittgensteinian analysis of the anatomy and genealogy of 'anger' aptly characterises forms of 'anger' that have arisen in history. What it does

3 Owen Gingerich, 'The Inside Story of Pluto's Demotion,' Sky \& Telescope 112, no. 11 (2006): 34-39.

4 Sara I. Walker, N. Packard, and G. D. Cody, 'Re-Conceptualizing the Origins of Life,' Philosophical Transactions of the Royal Society A 375, no. 20160337 (2017): 1-11.

5 Beverley Fehr and James A. Russell, 'Concept of Emotion Viewed from a Prototype Perspective,' Journal of Experimental Psychology: General 113, no. 3 (1984): 464-86.

6 For the Aristotelian approach see Steven Soter, 'What Is a Planet?', Scientific American 296, no. 1 (2007): 34-41. For the Wittgensteinian approach see Gingerich, 'The Inside Story.'

7 Klaus R. Scherer, 'What are Emotions? And How Can They be Measured?' Social Science Information 44, no. 3 (2007): 695-729; Richard A. Shweder, 'Toward a Deep Cultural Psychology of Shame,' Social Research 70, no. 4 (2003): 1109-30.

8 Fehr and Russell, 'Concept of Emotion'; W. Gerrod Parrott, 'Components and the Definition of Emotion,' Social Science Information 44, no. 3 (2007): 419-23. 
not do, however, is explain why these emotions are considered forms of 'anger' and why other emotions are not. That is, why does an essay on the history of 'anger' address the nature of mênis, orgēe, ira, yrre and liget, but not aidōs, phthonos, acedia, scand or amae? The answer cannot be that only words from the first set have been suggested as translations of 'anger' in various bilingual dictionaries - that answer would merely pass the problem over to the lexicographers. A satisfactory answer must specify ways in which mênis is more similar to anger than is aidōs or phthonos. Although Dixon does not detail the basis of that similarity, he clearly signals a readiness to do so by stating his acceptance of some sort of shared humanity that spans historical and cultural differences. That is not the only solution to the problem, but it is one way to avoid, as he puts it, 'drowning in relativism'.

To conclude as provocatively as possible, I would like to argue that Dixon's point about shared humanity could be extended beyond humans. When Dixon allows that there may be 'biological and neurological affinities shared among all humans', I would add that there may also be biological and neurological affinities shared among all primates, and even among all mammals. Jane Goodall, for example, has argued that chimpanzees have emotional lives that recognisably overlap those of humans, and that the neurological similarities between the species make her conclusions plausible. ${ }^{9}$ Considerable further observation has led to a robust multi-disciplinary literature on animal emotions. ${ }^{10}$ The details and implications of that literature are beyond the scope of this commentary, but obviously they limit relativist claims of human exceptionalism and temper accounts that emphasise the linguistic labelling of emotions. The contributions of history to the study of emotion will be most profound and consequential when they are engaged as part of a multidisciplinary enterprise.

9 Jane Goodall, Through a Window: My Thirty Years with the Chimpanzees of Gombe (Boston: Houghton Mifflin, 1990).

10 Frans de Waal, Mama's Last Hug: Animal Emotions and What They Tell Us about Ourselves (New York: Norton, 2019); W. Gerrod Parrott, 'Ur-Emotions: The Common Feature of Animal Emotions and Socially Constructed Emotions,' Emotion Review 4 no. 3 (2012): 247-48; Robert C. Roberts, 'The Sophistication of Non-Human Emotion' in The Philosophy of Animal Minds, ed. Robert W. Lutz (Cambridge, UK: Cambridge University Press, 20o9), 218-36. 